DIW BERLIN

Discussion Papers

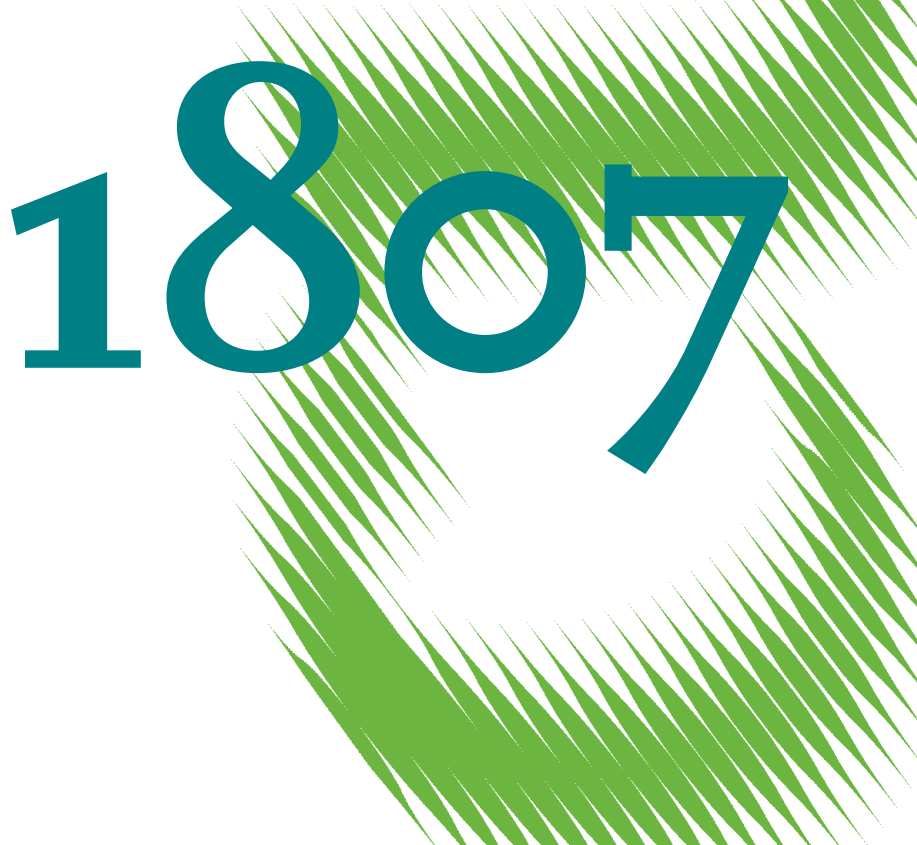

Environmental Policy and Firm Selection in the Open Economy 
Opinions expressed in this paper are those of the author(s) and do not necessarily reflect views of the institute.

IMPRESSUM

(C) DIW Berlin, 2019

DIW Berlin

German Institute for Economic Research

Mohrenstr. 58

10117 Berlin

Tel. +49 (30) $89789-0$

Fax +49 (30) $89789-200$

http://www.diw.de

ISSN electronic edition 1619-4535

Papers can be downloaded free of charge from the DIW Berlin website:

http://www.diw.de/discussionpapers

Discussion Papers of DIW Berlin are indexed in RePEc and SSRN:

http://ideas.repec.org/s/diw/diwwpp.html

http://www.ssrn.com/link/DIW-Berlin-German-Inst-Econ-Res.html 


\title{
Environmental Policy and Firm Selection in the Open Economy*
}

\author{
Udo Kreickemeier $^{\dagger}$ \\ University of Göttingen \\ CESifo and GEP
}

\author{
Philipp M. Richter ${ }^{\ddagger}$ \\ TU Dresden \\ CESifo, DIW Berlin, and KCG
}

June 21, 2019

\begin{abstract}
In this paper, we analyse the effects of a unilateral change in an emissions tax in a model of international trade with heterogeneous firms. We find a positive effect of tighter environmental policy on average productivity in the reforming country through reallocation of labour towards exporting firms. Domestic aggregate emissions fall, due to both a scale and a technique effect, but we show that the reduction in emissions following the tax increase is smaller than in autarky. Moreover, general equilibrium effects through changes in the foreign wage rate lead to a reduction in foreign emissions and, hence, to negative emissions leakage in case of transboundary pollution.
\end{abstract}

JEL codes: F18, F12, F15, Q58

Keywords: Trade and environment; Heterogeneous firms; Unilateral environmental policy; Emissions leakage

\footnotetext{
${ }^{*}$ We thank Jevan Cherniwchan, Michael Koch, Miriam Kohl, and Pauli A. Lappi as well as the participants at the Conference on Sustainable Resource Use and Economic Dynamics of ETH Zurich, the World Congress of Environmental and Resource Economists in Gothenburg; the Annual Conference of the European Trade Study Group in Warsaw, the Workshop on International Economics in Göttingen, and the seminar participants at the TU Dresden for helpful comments and discussion.

${ }^{\dagger}$ University of Göttingen, Faculty of Business and Economics, Platz der Göttinger Sieben 3, 37073 Göttingen, Germany; Email: udo.kreickemeier@uni-goettingen.de.

${ }_{\ddagger}^{\ddagger}$ Technische Universität Dresden, Faculty of Business and Economics, Helmholtzstraße 10, 01069 Dresden, and DIW Berlin department of Energy, Transportation, Environment, Mohrenstr. 58, 10117 Berlin, Germany; Email: philipp_moritz.richter@tu-dresden.de.
} 


\section{Introduction}

The effectiveness of unilateral environmental policy in a globalised world remains a key question for research and policy-makers alike. Unilateralism is a common theme in global climate policy, for instance. It is an imminent feature of the Paris (Climate) Agreement, where countries individually decide on greenhouse gas emissions reductions, the so-called nationally determined contributions (cf. UNFCCC, 2015). Key concerns address both a potential negative impact on domestic manufacturing and a poor environmental effectiveness due to carbon leakage. ${ }^{1}$ Both concerns impede the implementation of ambitious policies to begin with.

We address these issues focusing on effects at the firm level, where we highlight the role of firm behaviour in case of firm heterogeneity in productivity and emissions intensity. The main question we are interested in is the effect of a change in the domestic emissions tax rate on aggregate emissions at home and abroad. In particular, we analyse how the impact on domestic emissions is altered by the fact that the economy is open and show how this is related to a change in the distribution of active firms.

To this end, we develop a general equilibrium trade model with heterogeneous firms à la Melitz (2003), to which we add an emissions-generating process based on Copeland and Taylor (1994). Accordingly, each active firm endogenously determines how much labour to employ in production, and how much to use for abatement. Countries are asymmetric, as in Felbermayr et al. (2013), and in reaction to a unilateral change in the emissions tax the firm distribution, the labour allocation across firms and within each firm across usage, and the tax-wage ratios in both countries endogenously adjust in general equilibrium. Jointly, these effects determine the change in domestic and foreign emissions. The model remains analytically tractable, and we provide closed-form solutions for all relevant elasticities.

We show that in the presence of international trade in goods a unilateral increase in the emissions tax raises the economy-wide average productivity in the reforming country. The least productive firms stop producing, while resources are shifted to exporting firms, which are both more productive and less emissions intensive than the average of domestic firms. This shift towards exporting activity is due to a decline in the relative market size of the reforming country induced by the tax increase. With its focus on an induced rise in productivity due to the general equilibrium across-firms reallocation of resources, our model gives an alternative rationale for

\footnotetext{
${ }^{1}$ See Aichele and Felbermayr (2015) on the empirical relevance of shifts in the carbon content of trade flows due to climate policies initiated by the Kyoto Protocol. In a structural gravity model, Larch and Wanner (2017) show how carbon tariffs could reduce carbon leakage.
} 
the Porter Hypothesis (Porter and Van der Linde, 1995), observed at an aggregate level. ${ }^{2}$ We show that this mechanism crucially depends on both international trade and asymmetric environmental policy changes, as in our model framework it is neither present under autarky nor in the case of internationally coordinated environmental policy.

We further show that the reallocation of labour towards exporting firms is complemented by a within-firm reallocation of labour towards emissions abatement. The resulting decline in aggregate emissions is due to both a scale effect and a technique effect, i.e. the economy develops towards a state of lower overall production, which is on average cleaner. Importantly, the direct effect of higher emissions pricing is amplified by an induced decline in the wage rate. This mechanism holds both under autarky and in the open economy. However, we show that aggregate emissions are less elastic with respect to changes in the emissions tax when the economy is open. The reason is a smaller decline in the demand for labour in production due to the opportunity to export leading to the across-firms reallocation of labour towards the more productive exporters.

Moreover, we find that the reduction in the market size of the reforming country induced by the more stringent environmental policy transmits to its trading partner, and we show that via general equilibrium adjustments foreign aggregate emissions decrease as well. In case of transboundary pollution this environmentally beneficial effect feeds back to the reforming country. All other things equal, environmental effectiveness rises due to this channel of negative emissions leakage. Our result of negative emissions leakage relies on a general equilibrium effect on the tax-wage ratio in the foreign country induced by the decline in the relative market size of its trading partner, the reforming country. The foreign wage falls relative to the unchanged foreign emissions tax, inducing a reallocation of labour towards abatement in the foreign country.

This channel is different from, and complementary to, other rationales for negative emissions leakage that have been put forward in the literature. In Baylis et al. (2014) the mobility of a clean input (e.g. labour or capital) across countries leads to the decline in foreign production and, hence, foreign emissions. Other frameworks generate negative emissions leakage through international spillovers of green technologies (cf. Di Maria and Werf, 2008) or endogenous changes in the foreign environmental policy (cf. Copeland and Taylor, 2005). ${ }^{3}$ In a small open economy (within an intra-industry trade model with homogeneous firms) Holladay et al. (2018) highlight

\footnotetext{
${ }^{2}$ According to the ('strong version' of the) Porter Hypothesis stricter environmental policy may push regulated firms to a more profitable state as it triggers innovation, for instance, and individual firms become more productive. Ambec et al. (2013) provides a recent survey of the theoretical explanations and the empirical evidence on the Porter Hypothesis.

${ }^{3}$ See Baylis et al. (2014) for a broader discussion on how to decompose the overall leakage effect into partial effects in computational general equilibrium (CGE) models.
} 
the role of trade costs in a non-polluting sector ("services") for emissions leakage. For a services importer, higher trade costs in this sector increase emissions leakage, partly by dampening an effect of negative emissions leakage from reduced domestic consumption of the polluting good. Also in a monopolistic competition trade model with homogeneous firms Gürtzgen and Rauscher (2000) derive a channel of negative leakage by allowing for endogenous markups and linking emissions to the number of firms. A change in the domestic emission standard alters the market-structure and may lead to reduced foreign emissions.

Our paper contributes to a literature that analyses the effect of (trade and environmental) policy changes on environmental quality in open economies, focusing on the micro level and accounting for firms' heterogeneous responses. ${ }^{4}$ Kreickemeier and Richter (2014) show how unilateral trade liberalisation may affect aggregate emissions, even in the absence of emissions pricing, through the reallocation of resources across firms that differ in emissions intensities. Forslid et al. (2018) develop a model in which firms can decide on how much to invest in order to reduce their emissions intensity. An exporting firm with larger sales can more easily spread the investment costs across supplied volumes and invest more. A reduction in trade costs increases the difference in emissions intensity to non-exporting firms due to changes in relative sales. LaPlue (2019) develops a two-sector model with firm heterogeneity extending Bernard et al. (2007), in which one sector is polluting and countries differ in their relative factor endowments of labour and capital. He then focuses on intra-sectoral and inter-sectoral composition effects of trade liberalisation on aggregate emissions, and shows how these effects interact. ${ }^{5}$ In contrast to all these papers, which focus on the effects of trade policy changes on the environment, we analyse in this paper the effects of a unilateral change in environmental policy. Two types of reallocation effects interact in the adjustment to the change in the emissions tax rate: a withinfirm reallocation of resources between the production process and emissions abatement, and the across-firms reallocation of labour towards exporters. Both reallocation effects can be viewed as micro-foundations of the technique effect that subsumes (trade and environmental) policy induced changes in aggregate emissions intensities. ${ }^{6}$

Our paper is also related to the literature on the impact of environmental regulation in

\footnotetext{
${ }^{4}$ For a recent survey see Cherniwchan et al. (2017).

${ }^{5}$ Barrows and Ollivier (2018) develop a model with multi-product firms, where emissions-intensities differ across products within each firm. Changes in (trade) policy affect aggregate emissions through the heterogeneous reaction of firms in altering their product mix'. In the model of Forslid et al. (2017), which abstracts from differences between firms, it is the interaction between relative country size and relative emissions taxes that matters for firm location and emissions. Despite higher environmental standards, a large country may attract polluting firms due to the home market effect, while global emissions decline in this case. The model of Pflüger (2001) is based on a similar mechanism.

${ }^{6}$ The technique effect is found to play an important role in changes in aggregate emissions (cf. Shapiro and Walker, 2018; Cherniwchan, 2017; Levinson, 2009; Antweiler et al., 2001).
} 
closed-economy models with heterogeneous firms. It is a potential loss in varieties (i.e. a net reduction of supplying firms) that Andersen (2018) characterises as indirect welfare costs of regulation. Anouliès (2017) and Konishi and Tarui (2015) analyse the environmental and economic effects of an emissions trading scheme (ETS) with different forms of allocation rules. Tombe and Winter (2015) and Li and Sun (2015), in turn, derive differences between taxes and standards, while Cao et al. (2016) and Andersen (2016) focus on investments in abatement technology. Najjar and Cherniwchan (2018) distinguish between two upgrade options; one that only reduces the emissions intensity and another that additionally leads to an increase in labour productivity at higher fixed costs. In line with a recent Canadian environmental policy reform, only firms without any of the two options are affected, which induces selection and reallocation effects. In this paper we complement this literature by focussing on the effects of environmental policy in an economy open to international trade. We show how both the exchange of manufactured goods and emissions spillovers influence the effectiveness of domestic policy changes when heterogeneous firms in both trading countries adjust. Asymmetry in environmental policy reforms turns out to be decisive.

The remainder of the paper is organised as follows. Section 2 introduces the model and analyses the effects of an environmental policy reform under autarky. Section 3 extends the model to the open economy case with asymmetric countries, while Section 4 solves for the impact of a unilateral change in environmental policy on firm selection and aggregate emissions in both trading countries. Section 5 provides additional results on a coordinated environmental policy reform and presents a decomposition of aggregate emissions. Section 6 concludes.

\section{Environmental policy reform in the closed economy}

We consider an economy that is endowed with $L$ units of labour and that produces two types of goods, a homogeneous final good and a differentiated intermediate good. Emissions $E$ are generated in the production process of the intermediate good.

\subsection{The model: basics}

The final good is produced under perfect competition from all available varieties of the intermediate good (cf. Egger and Kreickemeier, 2009; Ethier, 1982). Production of the final good is represented by a standard CES production function with $\sigma>1$ as the elasticity of substitution 
between varieties. Accordingly,

$$
Y=\left[\int_{v \in V} q(v)^{\frac{\sigma-1}{\sigma}} d v\right]^{\frac{\sigma}{\sigma-1}}
$$

where $q(v)$ denotes the demand for variety $v$ out of the set of all available varieties $V$. Profit maximisation leads to the standard iso-elastic demand function $q(v)=Y P^{\sigma} p(v)^{-\sigma}$ for each variety, where $p(v)$ is the price of variety $v$ and $P$ denotes the ideal CES price index. ${ }^{7}$ We use the homogeneous final good as numéraire. In the intermediate goods sector, there is a continuum of firms of different productivity levels, with each firm producing a unique variety. Production generates emissions. Firms can use labour, $l$, both in their production process and in order to abate emissions, e. An individual firm's production technology is given by $y(\varphi)=\varphi \xi(\varphi) l(\varphi)$, with $\varphi$ as the exogenous productivity level that characterises a particular firm and $\xi(\varphi)$ as the endogenous share of variable labour input that is used in production.

We follow Copeland and Taylor (1994) and assume that firm-level emissions are given by

$$
e(\varphi)=[\xi(\varphi)]^{\frac{1}{1-\alpha}} l(\varphi)
$$

with $\alpha \in(0 ; 1)$. Hence, emissions are increasing and convex in $\xi(\varphi)$, and therefore the abatement technology exhibits a decreasing marginal efficiency with respect to the labour share used in abatement, $1-\xi(\varphi)$. Using Eq. (1) to substitute for $\xi(\varphi)$, we can re-write the production technology as

$$
y(\varphi)=\varphi[l(\varphi)]^{\alpha}[e(\varphi)]^{1-\alpha},
$$

where parameter $\alpha$ is the cost share of production labour in the production process. Accordingly, our specification is equivalent to treating emissions as an input into the production process. ${ }^{8}$

Treating parametrically the competitive wage rate $w$ and the emissions tax $t$ per unit of generated emissions, firms minimize their unit production cost, yielding factor demand functions

$$
l(\varphi)=\frac{y(\varphi)}{\varphi}\left(\frac{t}{w}\right)^{1-\alpha}\left(\frac{\alpha}{1-\alpha}\right)^{1-\alpha} \quad \text { and } \quad e(\varphi)=\frac{y(\varphi)}{\varphi}\left(\frac{w}{t}\right)^{\alpha}\left(\frac{1-\alpha}{\alpha}\right)^{\alpha}
$$

\footnotetext{
${ }^{7}$ We assume that households spend their entire income on the domestically produced final good, i.e. $P_{i} Y_{i}$. Income originates from labour income and revenues from an emissions tax that are lump-sum redistributed to households. In the open economy setup below, total income is increased by potential tariff revenues, which are lump-sum redistributed to households as well.

${ }^{8}$ See Copeland and Taylor (1994) or Copeland and Taylor (2004) for a motivation of this specific form of abatement.
} 
and a unit cost function

$$
c(\varphi)=\frac{\beta w^{\alpha} t^{1-\alpha}}{\varphi}, \quad \text { with } \quad \beta \equiv(1-\alpha)^{(\alpha-1)} \alpha^{-\alpha}
$$

Both factor demand functions depend on the wage-tax ratio facing the firm. Despite the apparent symmetry in the role played by $w$ and $t$, there is an important difference, in that the wage rate is an endogenous variable determined in general equilibrium, while the tax rate is a policy parameter.

Using Eq. (1), the share of variable labour input used for production follows as

$$
\xi=\left(\frac{1-\alpha}{\alpha}\right)^{1-\alpha}\left(\frac{w}{t}\right)^{1-\alpha}
$$

which shows that the firm-internal allocation of labour is independent of firm productivity. Plausibly, a lower emissions tax relative to the wage rate leads to a larger employment share being allocated to production rather than abatement. The firm-specific emission intensity is defined as $a(\varphi) \equiv e(\varphi) / y(\varphi)$, and substituting from above we find

$$
a(\varphi)=\left(\frac{1-\alpha}{\alpha}\right)^{\alpha}\left(\frac{w}{t}\right)^{\alpha} \varphi^{-1}
$$

The emission intensity is decreasing in $\varphi$, i.e. a more productive firm is more environmentally efficient, and increasing in the wage-tax ratio.

Firms compete under monopolistic competition. Selling a unique variety, each firm can charge a constant markup $\rho^{-1} \equiv \sigma /(\sigma-1)$ over its unit cost: $p(\varphi)=c(\varphi) / \rho$. Imposing goods market equilibrium, it follows that firm-level prices $p(\varphi)$ are decreasing in firm productivity $\varphi$ with elasticity -1 , while firm-level output $y(\varphi)$ and firm-level revenues $r(\varphi)$ are increasing in $\varphi$ with elasticities $\sigma$ and $\sigma-1$, respectively. Firm-level emission intensities and firm-level emissions also vary with firm productivity with constant elasticity. Specifically, for two firms with productivities $\varphi_{1}$ and $\varphi_{2}$, we have

$$
\frac{e_{i}\left(\varphi_{1}\right)}{e_{i}\left(\varphi_{2}\right)}=\left(\frac{\varphi_{1}}{\varphi_{2}}\right)^{\sigma-1} \quad \text { and } \quad \frac{a_{i}\left(\varphi_{1}\right)}{a_{i}\left(\varphi_{2}\right)}=\left(\frac{\varphi_{1}}{\varphi_{2}}\right)^{-1} .
$$

Hence, a more productive firm generates more emissions (due to its larger output) but has a lower emission intensity. ${ }^{9}$

\footnotetext{
${ }^{9}$ This matches well recent empirical findings at the firm-level (cf. Forslid et al., 2018; Richter and Schiersch, 2017; Holladay, 2016).
} 
Due to fixed-markup pricing, firm-level operating profits are a constant fraction $1 / \sigma$ of firmlevel revenues. With a fixed input requirement equal to $f$ units of labour, this implies that the productivity of the marginal firm, denoted by $\varphi^{d}$, is implicitly determined by the zero cutoff profit condition $\pi\left(\varphi^{d}\right)=r\left(\varphi^{d}\right) / \sigma-w f=0$. The productivity of final-good producers is drawn from a Pareto distribution $G(\varphi)=1-\varphi^{-k}$ with corresponding density function $g(\varphi)=k \varphi^{-(k+1)}$, where we assume $k>\sigma$ in order to ensure that the relevant model variables have finite means. With a Pareto distribution for productivities, average revenues are a constant multiple $\theta \equiv k /[k-(\sigma-1)]$ of the revenues for the marginal firm, and therefore the zero cutoff profit condition implies that average profits of active firms are equal to

$$
\bar{\pi}=(\theta-1) w f .
$$

Access to the productivity draw is costly, as in Melitz (2003), with fixed entry cost equal to $w f^{e}$. In equilibrium, the fixed entry cost is equal to the expected profits to be made in the market, which are given by average profits of active firms, $\bar{\pi}$, multiplied by the probability of getting a draw above the cutoff productivity $\varphi^{d}$, which is equal to $1-G\left(\varphi^{d}\right)$. Using the Pareto assumption, the free entry condition can be written as

$$
\bar{\pi}=w f^{e}\left(\varphi^{d}\right)^{k}
$$

Together, Eqs. (5) and (6) imply

$$
\varphi^{d}=\left[\frac{(\theta-1) f}{f^{e}}\right]^{\frac{1}{k}}
$$

and, hence, cutoff productivity $\varphi^{d}$ only depends on model parameters $\sigma, k, f$, and $f^{e}$.

\subsection{Aggregate emissions}

The main question we are interested in is the effect of a change in the domestic emissions tax rate on aggregate emissions. Below, we will compare this effect to the effect that arises in an economy open to international trade. Total emissions generated in autarky are given by

$$
E=M \bar{e},
$$

i.e. they are the product of the mass of firms and the average emissions per firm. We can derive the mass of firms $M$ from the full employment condition, according to which exogenous labour supply $L$ needs to be equal to the labour demand for the fixed-cost activities plus variable labour 
demand for production and abatement:

$$
L=\frac{M}{1-G\left(\varphi^{d}\right)} f^{e}+M f+M \bar{l},
$$

where $M /\left[1-G\left(\varphi^{d}\right)\right]>M$ is the mass of firms entering the productivity lottery, while $\bar{l} \equiv$ $\int_{\varphi^{d}}^{\infty} l(\varphi) g(\varphi) /\left[1-G\left(\varphi^{d}\right)\right] d \varphi$ is average variable labour input, where we use density-weights from the ex post equilibrium productivity distribution of active firms. As we show in the Appendix, the mass of active firms follows as

$$
M=\frac{L}{\zeta k f^{e}}\left(\varphi^{d}\right)^{-k},
$$

where we define $\zeta \equiv[1+\alpha(\sigma-1)] /(\sigma-1)$. Average emissions, in turn, are given by

$$
\bar{e}=\int_{\varphi^{d}}^{\infty} e(\varphi) \frac{g(\varphi)}{1-G\left(\varphi^{d}\right)} d \varphi=(1-\alpha) \theta(\sigma-1) f \frac{w}{t}
$$

which directly follows from the zero profit condition of the marginal firm and from the Pareto specification of the productivity distribution.

Using Eqs. (10) and (11), aggregate emissions can be derived as

$$
E=(1-\alpha) \frac{L(\theta-1) f}{\zeta f^{e}} \frac{w}{t}\left(\varphi^{d}\right)^{-k}=(1-\alpha) \frac{L}{\zeta} \frac{w}{t}
$$

where the second equality follows from Eq. (7). Accordingly, aggregate emissions solely depend on the wage-tax ratio. Intuitively, it is the wage-tax ratio that determines the economy-wide labour allocation between the production process and emissions abatement and that is, hence, crucial for the total economic activity and the aggregate emissions intensity. ${ }^{10}$

In order to derive the reaction of aggregate emissions to a change in environmental policy we express terms in percentage changes. In the open economy setting below, this technique of log-linearising non-linear relations is needed to find closed-form solutions, and for reasons of comparability it is employed here as well. Log-linearising aggregate emissions, Eq. (12), yields

$$
\hat{E}=\hat{w}-\hat{t}
$$

where the hat-notation denotes a percentage change, e.g. $\hat{E} \equiv d E / E$. As shown in the Appendix, in the closed economy the elasticity of the wage rate w.r.t. the domestic emissions tax is given

\footnotetext{
${ }^{10}$ We devote part of Section 5 to a discussion on the decomposition of aggregate emissions.
} 
by

$$
\frac{\hat{w}}{\hat{t}}=-\frac{1-\alpha}{\alpha}
$$

and hence an increase in the emissions tax leads to a reduction in the wage rate that is larger in absolute value if $\alpha$, the cost share of production labour, is small. It follows directly that $\hat{E} / \hat{t}=-1 / \alpha<-1$. We therefore have the following result:

Proposition 1. An increase in the emissions tax reduces aggregate emissions in the closed economy. The direct effect of the tax increase is amplified by an induced reduction in the wage rate, which gives a further incentive to reduce emission intensity at the firm level.

\section{Open economy equilibrium}

We now characterise the open economy equilibrium, allowing for asymmetry between two large countries, where we denote the home country of Section 2 by $i$ and the foreign country by $j$, respectively. In the following we focus on country $i$, while results equivalently hold for country $j$.

While we assume the final good non-tradable, we allow for (costly) trade in the differentiated intermediate good. ${ }^{11}$ Besides international trade, countries are linked by potential emissions spillovers of transboundary pollution. Accordingly, the effect of a unilateral environmental policy reform on domestic pollution may be different in the open economy than in the setting of autarky for two reasons. First, due to international trade the domestic economy and, hence, domestic aggregate emissions may respond differently to a change in the emissions tax rate. Second, trade in intermediates transmits the change in country $i$ 's emissions tax to the foreign country affecting foreign aggregate emissions, which spill over to the reforming country in case of transboundary pollution.

\subsection{The intermediate goods sector}

In the intermediate goods sector, each active firm decides whether to become an exporter given two types of export costs. First, there is a fixed input requirement of $f^{x}$ units of labour, where we assume $\tilde{f}^{x} \equiv f^{x} / f \geq 1$. Second, exports are subject to an ad-valorem tariff $\left(\tau_{j}-1\right) \geq 0$ imposed by the importing country. Accordingly, domestic exporters charge a price of $p_{j}(\varphi)=\tau_{j} c_{i}(\varphi) / \rho$

\footnotetext{
${ }^{11}$ Suppose, for instance, the final good production process is a refinement for the particular market or, alternatively, a form of retailing. We continue using the domestic CES-composite final good as numéraire. We show in an Online Appendix that our results remain valid if we choose the foreign final good as the numéraire instead.
} 
on the foreign market. Export revenues of a domestic firm with productivity $\varphi$ then follow as

$$
r_{i}^{x}(\varphi)=\tau_{j}^{-1}\left[Y_{j}\left(P_{j}\right)^{\sigma}\left(\frac{\tau_{j} \beta w_{i}^{\alpha} t_{i}^{1-\alpha}}{\rho \varphi}\right)^{1-\sigma}\right] .
$$

The zero cutoff profit conditions for entry in the domestic and export markets are given by

$$
\frac{r_{i}^{d}\left(\varphi_{i}^{d}\right)}{\sigma}-w_{i} f=0 \quad \text { and } \quad \frac{r_{i}^{x}\left(\varphi_{i}^{x}\right)}{\sigma}-w_{i} f^{x}=0
$$

respectively, where $\varphi_{i}^{x}$ denotes the productivity of the marginal exporting firm.

Due to the assumption of a Pareto distribution for productivities, the share of exporters in the total mass of active firms, $\chi_{i}$, can be expressed in terms of the two cutoff productivities:

$$
\chi_{i}=\frac{1-G\left(\varphi_{i}^{x}\right)}{1-G\left(\varphi_{i}^{d}\right)}=\left(\frac{\varphi_{i}^{d}}{\varphi_{i}^{x}}\right)^{k}
$$

In analogy to the closed economy, the zero cutoff profit conditions now allow us to write average profits across all domestic firms from both the domestic and the export market as

$$
\bar{\pi}_{i}=(\theta-1) w_{i}\left(f+f^{x} \chi_{i}\right)
$$

Together with the unchanged free entry condition, Eq. (6), the zero cutoff profit conditions imply the following relation between the two cutoff productivity levels in country $i$ :

$$
f\left(\varphi_{i}^{d}\right)^{-k}+f^{x}\left(\varphi_{i}^{x}\right)^{-k}=\frac{f^{e}}{\theta-1}
$$

Accordingly, in the open economy the two productivity cutoffs for the domestic and for the export market, respectively, are negatively related. The intuition is straightforward: The free entry condition implies that for given market entry cost a higher domestic cutoff - and hence a lower probability of getting a productivity draw above this cutoff - must be accompanied with a higher expected profit in case of a successful draw, i.e. a higher $\bar{\pi}_{i}$. Higher expected profits in turn require a higher share of firms that export, and therefore, for a given domestic productivity cutoff, a lower export productivity cutoff.

Finally, the balanced trade condition in our model can be written as

$$
\chi_{i} M_{i} \bar{r}_{i}^{x}=\chi_{j} M_{j} \bar{r}_{j}^{x}
$$


where $\chi_{i} M_{i}$ is the mass of exporting firms in country $i$ and $\chi_{j} M_{j}$ in country $j$, respectively. Using the zero cutoff profit conditions, Eq. (14), the share of exporting firms in our model can be written as

$$
\chi_{i}=\left[\tau_{j}^{-\sigma}\left(\tilde{f}^{x}\right)^{-1} \frac{Y_{j} P_{j}^{\sigma}}{Y_{i} P_{i}^{\sigma}}\right]^{\frac{k}{\sigma-1}} .
$$

It depends both on trade-related parameters, the foreign tariff and the relative size of fixed exporting costs to domestic production fixed costs, and on ratios of aggregate variables, i.e. the relative price index and relative aggregate income between the two countries. For instance, a larger size of the foreign economy leads to an increase in the share of exporters among domestic firms, ceteris paribus. We assume throughout that trade costs are sufficiently high relative to the size of the export market such that exporting is not chosen by all firms, i.e. $\chi_{i}$ is strictly smaller than one.

\subsection{Aggregate emissions}

Similar to Eq. (12) for the closed economy, we can derive aggregate emissions in country $i$ as

$$
E_{i}=M_{i}\left(\bar{e}_{i}^{d}+\chi_{i} \bar{e}_{i}^{x}\right)
$$

where $\bar{e}_{i}^{d}$ denote average emissions from domestically sold production and $\bar{e}_{i}^{x}$ average emissions from supplying the foreign country.

As in the closed economy case, it is straightforward to derive the mass of firms from the full employment condition. Relative to labour demand in the closed economy setting, as given in Eq. (9), in the open economy labour demand additionally originates from exporting activity: to comply with the fixed input requirements and to be employed in the production process and the abatement of emissions. Additional labour demand is thus given by $\chi_{i} M_{i}\left(f^{x}+\bar{l}_{i}^{x}\right)$, where $\bar{l}_{i}^{x} \equiv \int_{\varphi_{i}^{x}}^{\infty} y_{i}^{x}(\varphi) /\left(\varphi \xi_{i}\right) g(\varphi) /\left[1-G\left(\varphi_{i}^{x}\right)\right] d \varphi$ denotes average variable labour demand from export supply. As shown in the Appendix, it turns out that the closed economy result still holds and the mass of domestic firms is given by Eq. (10). However, the domestic productivity cutoff it depends on, possibly is different when country $i$ is open to international trade. Average emissions, in turn, are determined as

$$
\bar{e}_{i}^{d}=(1-\alpha) \theta(\sigma-1) f\left(\frac{w_{i}}{t_{i}}\right) \quad \text { and } \quad \bar{e}_{i}^{x}=(1-\alpha) \theta(\sigma-1) f^{x}\left(\frac{w_{i}}{t_{i}}\right)
$$

where we weigh firm emissions, from Eq. (2), by means of the ex post equilibrium distributions 
of domestic firms, $g(\varphi) /\left[1-G\left(\varphi_{i}^{d}\right)\right] d \varphi$ and of exporting firms, $g(\varphi) /\left[1-G\left(\varphi_{i}^{x}\right)\right] d \varphi$, respectively.

Eqs. (17), (20) and (21) imply that aggregate emissions of country $i$ are given by

$$
E_{i}=(1-\alpha) \frac{L_{i}(\theta-1)}{\zeta f^{e}} \frac{w_{i}}{t_{i}}\left[f\left(\varphi_{i}^{d}\right)^{-k}+f^{x}\left(\varphi_{i}^{x}\right)^{-k}\right]=(1-\alpha) \frac{L_{i}}{\zeta} \frac{w_{i}}{t_{i}}
$$

Hence, we have the following result:

Lemma 1. Aggregate domestic emissions in the open economy depend solely on model parameters and on the wage-tax ratio.

\section{Unilateral environmental policy reform}

In this section, we analyse the effects of a unilateral increase in the emissions tax of country $i$ when it is open to international trade. We thereby focus on the impact on environmental quality and on the variables environmental quality depends on, in particular cutoff productivities and the wage rates in the two countries.

As we show in the Appendix, by combining the equilibrium conditions from Section 3 we can characterise the open economy equilibrium by a system of six equations in the four cutoff productivity levels (two for each country) and the two wage rates. Due to non-linearities, we follow Felbermayr et al. (2013) and Kreickemeier and Richter (2014) and log-linearise the system of equations, which allows us to find closed-form solutions in percentage-change notation. The resulting system of six equations in the six unknowns $\hat{\varphi}_{i}^{d}, \hat{\varphi}_{i}^{x}, \hat{\varphi}_{j}^{d}, \hat{\varphi}_{j}^{x}, \hat{w}_{i}$, and $\hat{w}_{j}$ is given by:

$$
\begin{aligned}
\hat{\varphi}_{i}^{d} & =-\tilde{f}^{x} \chi_{i} \hat{\varphi}_{i}^{x} \\
\hat{\varphi}_{j}^{d} & =-\tilde{f}^{x} \chi_{j} \hat{\varphi}_{j}^{x} \\
\hat{\varphi}_{j}^{x} & =\hat{\varphi}_{i}^{d}-\zeta\left(\hat{w}_{i}-\hat{w}_{j}\right)-(1-\alpha) \hat{t}_{i} \\
\hat{\varphi}_{i}^{x} & =\hat{\varphi}_{j}^{d}+\zeta\left(\hat{w}_{i}-\hat{w}_{j}\right)+(1-\alpha) \hat{t}_{i} \\
\hat{\varphi}_{i}^{x} & =\hat{\varphi}_{j}^{x}+\frac{1}{k}\left(\hat{w}_{i}-\hat{w}_{j}\right) \\
0 & =\tilde{\delta}_{i}\left[\alpha \hat{w}_{i}+(1-\alpha) \hat{t}_{i}+\frac{k-(\sigma-1)}{\sigma-1} \hat{\varphi}_{i}^{d}\right]+\left(1-\tilde{\delta}_{i}\right)\left[\alpha \hat{w}_{j}+\frac{k-(\sigma-1)}{\sigma-1} \hat{\varphi}_{j}^{x}\right],
\end{aligned}
$$

where we have set $\hat{P}_{i}=0$ by choice of the numéraire and $\hat{t}_{j}=\hat{\tau}_{i}=\hat{\tau}_{j}=0$ by choice of our analysis in this section, ${ }^{12}$ and where we define $\tilde{\delta}_{i}$ as the expenditure share of domestically

\footnotetext{
${ }^{12}$ In the Appendix we present the log-linearised system of equations in general form.
} 
produced varieties in total expenditures of country $i$. It is determined as

$$
\tilde{\delta}_{i} \equiv \frac{M_{i} \bar{r}_{i}^{d}}{M_{i} \bar{r}_{i}^{d}+\tau_{i} \chi_{j} M_{j} \bar{r}_{j}^{x}}=\left(1+\tau_{i} \tilde{f}^{x} \chi_{i}\right)^{-1}
$$

where the second equality follows from the trade balance condition and equilibrium solutions of the mass of firms, $M_{i}$, and average revenues, $\bar{r}_{i}^{d}=\theta \sigma w_{i} f$ and $\bar{r}_{i}^{x}=\theta \sigma w_{i} f^{x}$. In the absence of an import tariff $\left(\tau_{i}=1\right)$, the expenditure share $\tilde{\delta}_{i}$ coincides with the revenue share of domestic sales in total sales in country $i$. With positive tariffs, however, domestic consumers pay more for imports than foreign exporting firms generate as revenues. From Eq. (23) it follows that $\tilde{\delta}_{i}$ is related to the elasticity between the two domestic cutoff productivity levels as $\hat{\varphi}_{i}^{d} / \hat{\varphi}_{i}^{x}=$ $-\tau_{i}^{-1}\left(1-\tilde{\delta}_{i}\right) / \tilde{\delta}_{i}$. Accordingly, if the (initial) expenditure share for domestic products is large, for instance due to low initial trade openness, this elasticity is small (in absolute terms). ${ }^{13}$

\subsection{Firm selection}

Let us first focus on firm selection in response to the environmental policy reform. To this end we solve the system of equations for the change in the domestic cutoff productivity levels w.r.t. a unilateral change in the domestic emissions tax. As shown in the Appendix, the effect of a change in $t_{i}$ on the export cutoff in country $i$ is given by

$$
\frac{\hat{\varphi}_{i}^{x}}{\hat{t}_{i}}=-(1-\alpha)\left(1+\tilde{f}^{x} \chi_{j}\right)(\mathcal{A} k)^{-1}<0
$$

where we define $\mathcal{A} \equiv\left[2+\tilde{f}^{x}\left(\chi_{i}+\chi_{j}\right)\right] \zeta-\left[1-\left(\tilde{f}^{x}\right)^{2} \chi_{i} \chi_{j}\right] k^{-1}>0$. Accordingly, a unilateral increase in the domestic emissions tax leads to a reduction in the domestic export cutoff productivity. The elasticity is largest (in absolute value) for small values of the cost share of labour, $\alpha$, and of the (initial) domestic share of exporters, $\chi_{i}$, while it is decreasing in the (initial) share of foreign exporting firms, $\chi_{j}$. Using relation Eq. (23), the effect on the marginal domestic productivity level follows as

$$
\frac{\hat{\varphi}_{i}^{d}}{\hat{t}_{i}}=(1-\alpha) \tilde{f}^{x} \chi_{i}\left(1+\tilde{f}^{x} \chi_{j}\right)(\mathcal{A} k)^{-1}>0
$$

which is strictly positive and smaller than unity but declining in $\alpha$ and increasing in $\chi_{i, j}$. For $\chi_{i} \rightarrow 0$ the elasticity converges to zero and we are back in the case of autarky as discussed in

\footnotetext{
${ }^{13}$ Note that allowing for asymmetry this elasticity can generally be as small as $-\tilde{f}^{x} \leq-1$, while it is restricted to minus one in case of symmetry. This is because $\chi_{i}$ can be large despite high trade costs, which happens if the foreign economy is large relative to the domestic one.
} 


\section{Section 2 .}

Jointly, the change in the two domestic productivity cutoffs leads to an ex ante ambiguous effect on the aggregate economy-wide productivity. On the one hand, the marginal domestic firm is now more productive, on the other hand, however, firms of lower productivity now use resources for exporting activity. Let us define aggregate productivity as the weighted harmonic mean of individual firm productivity levels taking into account relative output volumes. ${ }^{14}$ Accordingly,

$$
\bar{\varphi}_{i} \equiv\left[\int_{\varphi_{i}^{d}}^{\infty} \varphi^{-1} \frac{y_{i}^{d}(\varphi)+y_{i}^{x}(\varphi)}{\bar{y}_{i}} \frac{g(\varphi)}{1-G\left(\varphi_{i}^{d}\right)} d \varphi\right]^{-1}=\frac{k-(\sigma-1)}{k-\sigma} \frac{1+\tilde{f}^{x} \chi_{i}^{\frac{k-1}{k}}}{1+\tilde{f}^{x} \chi_{i}} \varphi_{i}^{d}
$$

where we use the ex post equilibrium productivity distribution of all active domestic firms throughout and, thus, calculate the average productivity based on the entire (active) firm population. According to Eq. (32), average productivity is not affected by the wage-tax ratio but determined by firm selection, which is reflected by the presence of both cutoff productivity levels. Log-linearising and simplifying, as shown in the Appendix, yields

$$
\frac{\hat{\bar{\varphi}}_{i}}{\hat{t}_{i}}=(k-1)\left(\frac{1-\chi_{i}^{1 / k}}{\tilde{f}^{x} \chi_{i}+\chi_{i}^{1 / k}}\right) \frac{\hat{\varphi}_{i}^{d}}{\hat{t}_{i}}>0 .
$$

These results are summarised as follows:

Proposition 2. A unilateral increase in the emissions tax by country $i$ reduces the productivity of the marginal exporter in country $i$, while it increases the productivity of the marginal producer as well as aggregate country-i productivity.

The positive effect of a tax increase on aggregate productivity in our model works exclusively through a composition effect due to the reallocation of labour to more productive firms. The productivity at the firm level is fixed by assumption, as in many models in the tradition of Melitz (2003). Hence, our model puts forward as an alternative to the Porter Hypothesis (cf. Porter and Van der Linde, 1995), which focuses on induced technological adjustment at the level of individual firms, as an explanation for this positive link between environmental regulation and productivity at the aggregate level. Our finding is also related to Qiu et al. (2018), who find a similar result in a closed economy with linear demand. Interestingly, in our model with

\footnotetext{
${ }^{14}$ Precisely, $\bar{\varphi}_{i}$ is the average productivity of labour that is used in the production process. Alternatively, one can define the average labour productivity more broadly as the average productivity of entire variable labour input, which yields $\xi_{i} \times \bar{\varphi}_{i}$, or using the entire labour supply as in Demidova and Rodríguez-Clare (2009) which yields $M_{i} \bar{q}_{i} / L_{i}$. Note further that $\bar{\varphi}_{i}$ is differently defined than the (sales-weighted) average productivity in Melitz (2003). The following result is valid for all these different measures of aggregate productivity.
} 
CES demand aggregate productivity is unaffected by environmental taxes if the economy is closed. As a consequence, our analysis throws into particularly sharp relief the role played by international trade, with the reallocation of labour from small domestic firms to large exporting firms providing the crucial link between environmental taxation and aggregate productivity.

In order to get an intuition for why the tax increase induces the reallocation of labour to exporting firms, we log-linearise Eq. (15) to get

$$
\frac{\hat{\chi}_{i}}{\hat{t}_{i}}=k\left(\frac{\hat{\varphi}_{i}^{d}}{\hat{t}_{i}}-\frac{\hat{\varphi}_{i}^{x}}{\hat{t}_{i}}\right)>0
$$

where the positive sign directly follows from Proposition 2. The share of domestic exporters rises, leading to the increase in average productivity. Now, recall from Eq. (19) that $\chi_{i}$ changes in the relative market size of both trading partners. Without a change in trade costs this implies that

$$
\frac{\hat{Y}_{i}+\sigma \hat{P}_{i}}{\hat{t}_{i}}<\frac{\hat{Y}_{j}+\sigma \hat{P}_{j}}{\hat{t}_{i}} .
$$

It is, hence, the increase of the effective relative size of the export market induced by the domestic tax increase that drives firm selection and the increase in domestic average productivity.

The opposite happens in the foreign country. The decline in relative market size of the country increasing the tax rate - which is the export market for the foreign country - lead to fewer exporters, and to firm entry at the lower end of the productivity distribution. With derivations deferred to the Appendix, we find

$$
\frac{\hat{\varphi}_{j}^{x}}{\hat{t}_{i}}=-\frac{1+\tilde{f}^{x} \chi_{i}}{1+\tilde{f}^{x} \chi_{j}} \frac{\hat{\varphi}_{i}^{x}}{\hat{t}_{i}}>0 \quad \text { and } \quad \frac{\hat{\varphi}_{j}^{d}}{\hat{t}_{i}}=-\frac{\tilde{f}^{x} \chi_{j}}{\tilde{f}^{x} \chi_{i}} \frac{1+\tilde{f}^{x} \chi_{i}}{1+\tilde{f}^{x} \chi_{j}} \frac{\hat{\varphi}_{i}^{d}}{\hat{t}_{i}}<0
$$

where in case of initial symmetry, the effects on the two foreign cutoffs are of the exact same size (in absolute values), but of different sign, than the effects on the two cutoffs of country $i$. Inferring from Eq (33), the changes in the cutoff productivity levels imply that the foreign average productivity decreases when the domestic emissions tax is unilaterally raised.

We summarise this result as follows:

Proposition 3. A unilateral increase in the emissions tax by country $i$ has a negative impact on aggregate productivity in the foreign country. The marginal productivity of producing firms in country $j$ decreases, while the marginal exporter's productivity increases. 


\subsection{Environmental quality}

\subsubsection{Change in domestic emissions}

We know from Eq. (22) that the impact of a unilateral increase in the domestic emissions tax on aggregate emissions solely depends on the change in the wage-tax ratio according to

$$
\frac{\hat{E}_{i}}{\hat{t}_{i}}=\frac{\hat{w}_{i}}{\hat{t}_{i}}-1,
$$

where, however, it is ex ante unclear how the wage rate is affected in the setting of international trade. In general equilibrium, there are different opposing partial effects that interact: from decisions at the level of the individual firm on labour allocation across usages and, additionally to the closed economy setting, through firm selection and the reallocation of labour to more productive firms.

As shown in the Appendix, the link between the endogenous change in the domestic wage rate and the exogenous change in the domestic emissions tax in the open economy can be written as

$$
\frac{\hat{w}_{i}}{\hat{t}_{i}}=-\frac{1-\alpha}{\alpha}\left(1-\frac{1+\tilde{f}^{x} \chi_{j}}{\mathcal{A} k}\left[\tilde{f}^{x} \chi_{i}+\frac{k}{\sigma-1}\left\{1-\frac{1+\tilde{f}^{x} \chi_{i}}{1+\tilde{f}_{i} \tilde{f}^{x} \chi_{i}}\right\}\right]\right)<0
$$

where the term in parentheses is strictly between zero and one. Hence, the overall effect is negative, but smaller in absolute terms than in the closed economy. Intuitively, the decline in the domestic wage rate induced by the unilateral increase in the domestic emissions tax is cushioned in the open economy through the option of exporting to country $j$, whose relative market size is increasing.

Lemma 2. A unilateral increase in the emissions tax by country $i$ reduces the (real) wage rate in country $i$. The effect is smaller in absolute value than in the closed economy.

From Lemmas 1 and 2, it jointly follows that a unilateral increase in the domestic emissions tax rate indeed reduces domestic emissions, taking into account all general equilibrium effects in the open economy. The decline in the domestic wage rate amplifies the emissions reduction from tightened environmental policy. This can be summarised as follows:

Proposition 4. A unilateral increase in the emissions tax by country $i$ leads to a decline in domestic aggregate emissions. This effect is less pronounced in the open economy than under autarky. 


\subsubsection{Emissions spillovers and domestic environmental quality}

Environmental quality in country $i$ does not only depend on domestic emissions, but - in case of transboundary pollution on foreign emissions as well. For this reasons we now look at the question of how an increase in the domestic emissions tax affects foreign emissions, $E_{j}$.

Since Eq. (22) holds analogously for country $j$, we have

$$
\frac{\hat{E}_{j}}{\hat{t}_{i}}=\frac{\hat{w}_{j}}{\hat{t}_{i}}
$$

i.e. foreign emissions are affected by the change in the domestic emissions tax via the latter's effect on the foreign wage rate. As shown in the Appendix, it is straightforward to derive the elasticity of the relative wage rate w.r.t. the domestic emissions tax as

$$
\frac{\hat{w}_{j}-\hat{w}_{i}}{\hat{t}_{i}}=(1-\alpha) \frac{\left[2+\tilde{f}^{x}\left(\chi_{i}+\chi_{j}\right)\right]}{\mathcal{A}}>0 .
$$

Hence, an increase in the domestic emissions tax rate leads to a rise in the relative foreign wage rate.

Substituting for $\hat{w}_{i} / \hat{t}_{i}$ from Eq. (36), we get $0>\hat{w}_{j} / \hat{t}_{i}>\hat{w}_{i} / \hat{t}_{i}$, where the derivation is deferred to the Appendix. We can summarise these findings as follows:

Lemma 3. A unilateral increase in the emissions tax by country $i$ leads to a reduction in the foreign wage rate. This reduction is smaller than the decline in the wage rate of reforming country $i$.

According to Eq. (37), the reduction in the foreign wage rate translates into a proportional reduction of foreign emissions, and therefore our model features negative emissions leakage. It is the consequence of the fact that with a declining foreign wage rate and an unchanged foreign emissions tax rate the tax-wage ratio - and with it the incentive for abatement at the firm level - increases in the foreign country. If the pollutant is transboundary, this positive environmental effect feeds back to the reforming country, and domestic pollution is unambiguously decreasing in the domestic emissions tax.

In the effort to compare the effectiveness of an increase in the emissions tax for reducing domestic pollution we now have identified two effects that work in opposite directions: on the one hand, domestic emissions are reduced more strongly by an increase in the emissions tax if the economy is not open to international trade. On the other hand, with international trade there is an induced reduction in foreign emissions, and therefore an additional reduction of domestic 
pollution in the presence of international pollution spillovers.

In order to see what can be said about the overall effect, we specify pollution in country $i$ as the linear function $D_{i} \equiv E_{i}+\gamma E_{j}$, where parameter $\gamma \in[0,1]$ denotes the degree of spillover of emissions across national borders. Accordingly, the case of a purely local pollutant is given by $\gamma=0$, while $\gamma=1$ denotes the case of a global pollutant. Deriving the elasticity of domestic pollution, $D_{i}$, w.r.t. the domestic emissions tax then yields

$$
\frac{\hat{D}_{i}}{\hat{t}_{i}}=\frac{E_{i}}{E_{i}+\gamma E_{j}} \frac{\hat{E}_{i}}{\hat{t}_{i}}+\frac{\gamma E_{j}}{E_{i}+\gamma E_{j}} \frac{\hat{E}_{j}}{\hat{t}_{i}}
$$

where changes in aggregate emissions of each country are weighted by initial shares in country i's pollution. Using Eqs. (35), (37), and (38) this can be rewritten as

$$
\frac{\hat{D}_{i}}{\hat{t}_{i}}=\frac{\hat{w}_{i}}{\hat{t}_{i}}-\frac{E_{i}}{E_{i}+\gamma E_{j}}+\frac{\gamma E_{j}}{E_{i}+\gamma E_{j}}(1-\alpha) \frac{\left[2+\tilde{f}^{x}\left(\chi_{i}+\chi_{j}\right)\right]}{\mathcal{A}},
$$

which we have to compare to the corresponding expression in autarky, $\hat{D} / \hat{t}=\hat{E} / \hat{t}=\hat{w} / \hat{t}-1$.

From Lemma 2 we know that $\hat{w}_{i} / \hat{t}_{i}$ is larger in the closed economy. Further, as it is a share, the second term in Eq. (39) cannot exceed unity, while the third term is positive (although declining in the initial trade openness, see above). Jointly, it directly follows that the elasticity of domestic pollution, w.r.t. the domestic emissions tax is unambiguously smaller in the open economy (in absolute terms). Hence, environmental policy is more effective under autarky.

We summarise these results as follows:

Proposition 5. A unilateral increase in the emissions tax by country $i$ leads to a reduction in foreign emissions through an internationally-transmitted change in the foreign wage rate. In case of transboundary pollution this leads to negative emissions leakage. Relative to autarky, this partial effect is dominated by the smaller reduction in domestic aggregate emissions. Accordingly, a unilateral increase in the emissions tax reduces domestic pollution more effectively in the absence of international trade.

\section{Discussion}

In this section, we briefly discuss two additional aspects of our model. First, we look at coordinated policy reforms between the two countries. Second, we show how we can decompose the overall effect of tax reform on aggregate emissions into a scale effect and a technique effect. 


\subsection{Coordinated environmental policy reforms}

In this section, we complement our analysis of unilateral reform of environmental taxation with a discussion of the case of a coordinated environmental policy reform of the two trading partners. To this end, suppose both countries changed their emissions taxes by the same percentage, i.e. $\hat{t}_{i}=\hat{t}_{j}=\hat{t}$. This is more general than, but includes, the case of an equal change in emissions taxes (in levels) evaluated at a symmetric initial equilibrium.

By inspection of the system of equilibrium equations, a change in both emissions taxes of equal size does neither affect any cutoff productivity level in the two countries nor does it change the relative wage rate (which may still be different to unity as we allow for asymmetry). The intuition is as follows. Since we have an equally strong increase in the emissions taxes in both countries, the relative market attractiveness remains unchanged. Accordingly, we do not see a reallocation of labour to, or from, exporting firms, and the average productivity is not affected via the firm selection effect.

Moreover, we show in an Online Appendix that the elasticity of the domestic wage rate w.r.t. the domestic emissions tax is equal to $-(1-\alpha) / \alpha$. This leads to an elasticity of domestic aggregate emissions w.r.t. the domestic emissions tax equal to $-1 / \alpha$. Both elasticities are, hence, independent of initial values of endogenous variables and equal for both countries, even in case of initial asymmetry (changes in levels are not necessarily identical, of course). Moreover, these are the same elasticities as in the closed economy setting. It is, hence, not the difference between autarky and international trade that leads to the different impact of environmental policy. By contrast, it is the difference between unilateral and coordinated environmental policy in the open economy that has an impact on its effectiveness.

\section{$5.2 \quad$ Decomposing aggregate emissions}

There is a long tradition in the trade and environment literature to decompose the change in aggregate emissions in response to a trade or environmental policy reform into different partial effects (cf. Grossman and Krueger, 1993; Antweiler et al., 2001). This helps to better understand the underlying mechanisms behind the net effect. Recent decomposition approaches focus on the micro level using firm- and product-level data (Shapiro and Walker, 2018; Barrows and Ollivier, 2018; Cherniwchan et al., 2017).

In our framework, we can decompose aggregate emissions generated in country $i$ based on information of individual firm characteristics and on the equilibrium firm distribution. Accord- 
ingly,

$$
E_{i}=M_{i} \times \xi_{i} \times \bar{l}_{i} \times \bar{\varphi}_{i} \times \bar{a}_{i}=Q_{i} \times \bar{a}_{i},
$$

i.e. they are the product of total production $Q_{i}$ and average emission intensity of firms, where the latter is defined as $\bar{a}_{i} \equiv \int_{\varphi_{i}^{d}}^{\infty} a_{i}(\varphi)\left[y_{i}^{d}(\varphi)+y_{i}^{x}(\varphi)\right] / \bar{y}_{i} g(\varphi) /\left[1-G\left(\varphi_{i}^{d}\right)\right] d \varphi$. Total output, in turn, is the product of the mass of firms, the share of variable labour used in production, the average variable labour input, and the average productivity. ${ }^{15}$

Log-linearising Eq. (40), as shown in the Online Appendix, we can express the change in total domestic emissions as follows

$$
\hat{E}_{i}=\hat{Q}_{i}+\hat{\bar{a}}_{i}=\left[(1-\alpha)\left(\hat{w}_{i}-\hat{t}_{i}\right)+\hat{\bar{\varphi}}_{i}\right]+\left\{\alpha\left(\hat{w}_{i}-\hat{t}_{i}\right)-\hat{\bar{\varphi}}_{i}\right\}
$$

It consists of two partial effects: the scale effect (in square brackets), which collects all terms affecting aggregate emissions via a change in total production holding the emissions intensity constant, and the technique effect (in curly brackets), which measures the change in the (outputweighted) average emission intensity holding total production fixed.

Both the scale effect and the technique effect are determined by two channels: First, they are affected by changes in the wage-tax ratio that determines allocation of labour between production and emissions abatement. It, hence, corresponds to a within-firm reallocation effect. ${ }^{16}$ Second, both effects are affected by a change in average productivity. This corresponds to an across-firms reallocation effect. ${ }^{17}$ In our framework, the effect of average productivity on average emission intensity cancels its effect on output, which is due to the fact that, as shown in Eq. (4), firm-level emission intensity is inversely proportional to firm-level productivity. Hence, any reallocation of labour towards more productive firms, say, which increases average productivity, has an equal but opposite effect on average emission intensity. Hence, as shown above, only the within-firm reallocation effect determines aggregate emissions.

In case of a unilateral increase in the emissions tax as discussed in Section 4 we find an increase in average productivity in country $i$ (see Proposition 2). Joint with the decline in the wage-tax-ratio the technique effect is unambiguously negative, while the scale effect consists of two opposing effects. We show, however, in the Online Appendix that the within-firm realloca-

\footnotetext{
${ }^{15}$ While the decomposition is structurally equivalent in the open and closed economy, the different terms follow different equilibrium conditions in the open economy, which we will focus on in what follows.

${ }^{16}$ Alternatively, one may speak of a firm abatement effect (or 'pure' technique effect) as is based on individual firm decisions regarding emissions abatement.

${ }^{17}$ While there is no composition effect present in the traditional sense (cf. Antweiler et al., 2001) as we model only one sector, reallocation of labour across firms can be interpreted as intra-sectoral composition effect (cf. Kreickemeier and Richter, 2014).
} 
tion effect dominates and the scale effect is negative in response to an increase in $t_{i}$. Thus, both partial effects contribute to the decline in domestic aggregate emissions.

\section{Conclusions}

In this paper, we analyse the effects of a unilateral change in environmental policy in an open economy, using a model in which the firm population is exogenously heterogeneous with respect to firm productivity, and endogenously heterogeneous regarding firm-level emissions intensity, with more productive firms being more environmentally efficient. Countries are asymmetric, and due to fixed costs of exporting only the large, productive firms in both countries select into exporting.

Aggregate productivity increases in the country that increases its emissions tax unilaterally since productive exporting firms are less affected, in relative terms, by the tax-induced decrease in the domestic market size, and as a result they become relatively larger, carrying more weight in computing the average. By contrast, average productivity declines in the non-reforming trading partner, as foreign exporters face the relative decline in market size of the reforming country.

Through general equilibrium effects, wage rates in both countries are affected. This influences the efficiency of the unilateral environmental policy reform as it is the costs of emitting relative to the costs of emissions abatement that determines aggregate emissions. Accordingly, domestic emissions decline due to within-firm reallocation of labour towards emissions abatement that is amplified by a reduced wage rate. However, we show that in the open economy the elasticity of domestic aggregate emissions with respect to the domestic emissions tax is reduced relative to autarky. In this sense, unilateral environmental policy in our model is less effective in the presence of international goods trade than under autarky. Importantly, we find an internationally-transmitted decline in the foreign wage, which increases the tax-wage ratio abroad and, hence, leads to enhanced abatement efforts of foreign firms. In case of transboundary pollution this implies negative emissions leakage. 


\section{A Appendix}

\section{A.1 Environmental policy reform in the closed economy}

\section{A.1.1 Derivation of the mass of firms in Eq. (10)}

Due to the properties of the assumed Pareto distribution, we can express average variable labour input as a multiple of the variable labour input of the marginal firms scaling it by $\theta$. Accordingly, we can rewrite the full employment condition in Eq. (9) as

$$
L=M\left[f^{e}\left(\varphi^{d}\right)^{k}+f+\theta l\left(\varphi^{d}\right)\right]
$$

From the revenues of the marginal firm it follows that $y\left(\varphi^{d}\right)=\sigma f w\left[p\left(\varphi^{d}\right)\right]^{-1}$. Using this expression, the pricing rule, and the production technology, i.e. $l(\varphi)=y(\varphi) /[\varphi \xi(\varphi)]$, we can rewrite the full employment condition as:

$$
L=M\left[f^{e}\left(\varphi^{d}\right)^{k}+f(1+\theta(\sigma-1) \alpha)\right]
$$

Substituting the average profits condition, Eq. (5), for $f$ gives

$$
L=M\left[f^{e}\left(\varphi^{d}\right)^{k}+\frac{\bar{\pi}}{w(\theta-1)}(1+\theta(\sigma-1) \alpha)\right]
$$

Using the free entry condition, Eq. (6), to substitute for $\bar{\pi} / w$ gives

$$
L=M f^{e}\left(\varphi^{d}\right)^{k}\left[1+\frac{1+\theta(\sigma-1) \alpha}{\theta-1}\right]
$$

Finally, solving for $M$ and simplifying by means of the definition of $\zeta$ gives Eq. (10) in the main text.

\section{A.1.2 Derivation of the change in the wage rate in Eq. (13)}

The ideal CES price index is given by

$$
P^{1-\sigma}=\int_{\varphi^{d}}^{\infty} M[p(\varphi)]^{1-\sigma} \frac{g(\varphi)}{1-G\left(\varphi^{d}\right)} d \varphi
$$

Using the specification of the Pareto distribution for productivities, this can be rewritten as

$$
P^{1-\sigma}=M \theta\left[p\left(\varphi^{d}\right)\right]^{1-\sigma}
$$


By means of the equilibrium outcome for $M$ and $p(\varphi)$ this can be specified as

$$
P^{1-\sigma}=\frac{L \theta}{\zeta k f^{e}}\left(\frac{\beta t^{1-\alpha} w^{\alpha}}{\rho}\right)^{1-\sigma}\left(\varphi^{d}\right)^{\sigma-1-k}
$$

Log-linearising this term gives:

$$
(1-\sigma) \hat{P}=(1-\sigma)[\alpha \hat{w}+(1-\alpha) \hat{t}]+(\sigma-1-k) \hat{\varphi}^{d}
$$

Noting that $\hat{P}=0$ by choice of the numéraire and $\hat{\varphi}^{d}=0$, as from Eq. (7) $\varphi^{d}$ is fixed by parameters, we get Eq. (13) in the main text.

\section{A.2 Open economy equilibrium}

\section{A.2.1 Derivation of the mass of firms in the open economy}

The full employment condition for the open economy is given by

$$
\begin{array}{r}
L_{i}=M_{i}\left[f^{e}\left(\varphi_{i}^{d}\right)^{k}+f+\int_{\varphi^{d}}^{\infty} \frac{y_{i}^{d}(\varphi)}{\varphi \xi} \frac{g(\varphi)}{1-G\left(\varphi_{i}^{d}\right)} d \varphi\right. \\
\left.\quad+\chi_{i}\left(f^{x}+\int_{\varphi_{i}^{x}}^{\infty} \frac{y_{i}^{x}(\varphi)}{\varphi \xi} \frac{g(\varphi)}{1-G\left(\varphi_{i}^{x}\right)} d \varphi\right)\right] .
\end{array}
$$

By means of our specification of the Pareto distribution and of both zero cutoff profit conditions for country $i$ from Eq. (14), we can rewrite the full employment condition as

$$
L_{i}=M_{i}\left[f^{e}\left(\varphi_{i}^{d}\right)^{k}+\left(f+\chi_{i} f^{x}\right)(1+\theta(\sigma-1) \alpha)\right]
$$

Substituting Eq. (16) for $\left(f+\chi_{i} f^{x}\right)$, we get the same reduced equation as for the closed economy, Eq. (A.3). Since the free entry condition, Eq. (6), is unchanged, the mass of active domestic firms in the open economy is derived as in Eq. (10) as postulated in the main text.

\section{A.3 Unilateral environmental policy reform}

\section{A.3.1 Equilibrium relations and the log-linearised system of equations}

We derive the system of six generic equilibrium conditions as follows.

First, by means of the free entry condition and average firm profits we show in Eq. (17) a relation between the two cutoff productivity levels of country $i, \varphi_{i}^{d}$ and $\varphi_{i}^{x}$. 
Second, dividing the zero cutoff profit condition for foreign exporters to enter country $i$, by the zero cutoff profit condition for domestic firms to enter the same market, both from Eq. (14), we get an expression of the marginal domestic productivity level that depends on the relative wage rates, on relative emissions taxes, and as on the foreign export cutoff:

$$
\varphi_{i}^{d}=\left[\frac{1}{\tau_{i}^{\sigma}}\left(\frac{w_{i}}{w_{j}}\right)^{[1+\alpha(\sigma-1)]}\left(\frac{t_{i}}{t_{j}}\right)^{[(1-\alpha)(\sigma-1)]} \frac{f}{f^{x}}\right]^{\frac{1}{\sigma-1}} \varphi_{j}^{x}
$$

Third, making use of the trade balance condition, Eq. (18), simplified by average revenues, $\bar{r}_{i}^{d}=\theta \sigma w_{i} f$ and $\bar{r}_{i}^{x}=\theta \sigma w_{i} f^{x}$, by average profits from Eq. (16), and by the mass of firms from Eq. (10), we get

$$
\varphi_{i}^{x}=\left(\frac{L_{i}}{L_{j}} \frac{w_{i}}{w_{j}}\right)^{\frac{1}{k}} \varphi_{j}^{x}
$$

Finally, we make use of the domestic price index. Recall that for the open economy the domestic price index is a weighted average of individual prices from domestic and foreign suppliers. Accordingly,

$$
\begin{aligned}
P_{i}^{1-\sigma} & =\int_{\varphi_{i}^{d}}^{\infty} M_{i}\left(\frac{\beta w_{i}^{\alpha} t_{i}^{1-\alpha}}{\rho \varphi}\right)^{1-\sigma} \frac{g(\varphi)}{1-G\left(\varphi_{i}^{d}\right)} d \varphi+\int_{\varphi_{j}^{x}}^{\infty} \chi_{j} M_{j}\left(\frac{\tau_{i} \beta w_{j}^{\alpha} t_{j}^{1-\alpha}}{\rho \varphi}\right)^{1-\sigma} \frac{g(\varphi)}{1-G\left(\varphi_{j}^{x}\right)} d \varphi \\
& =\theta M_{i}\left(\frac{\beta w_{i}^{\alpha} t_{i}^{1-\alpha}}{\rho \varphi_{i}^{d}}\right)^{1-\sigma}+\theta \chi_{j} M_{j}\left(\frac{\tau_{i} \beta w_{j}^{\alpha} t_{j}^{1-\alpha}}{\rho \varphi_{j}^{x}}\right)^{1-\sigma},
\end{aligned}
$$

where the second line directly follows from the specified Pareto distribution. Using the definitions of the mass of domestic and exporting firms given in Eq. (10) this can be rewritten as

$$
P_{i}^{1-\sigma}=\frac{\theta}{\zeta k f^{e}}\left(\frac{\beta}{\rho}\right)^{1-\sigma}\left[L_{i}\left(w_{i}^{\alpha} t_{i}^{1-\alpha}\right)^{1-\sigma}\left(\varphi_{i}^{d}\right)^{\sigma-1-k}+L_{j}\left(\tau_{i} w_{j}^{\alpha} t_{j}^{1-\alpha}\right)^{1-\sigma}\left(\varphi_{j}^{x}\right)^{\sigma-1-k}\right]
$$

Note that $P_{i}$ is fixed due to our choice of the numéraire. Then Eqs. (17) and (A.11), and their respective analogues for country $j$, and Eqs. (A.12) and (A.14) jointly give a system of six equations in the six unknowns. This constitutes the open economy equilibrium. 
Log-linearising these six equations as shown in the Online Appendix yields

$$
\begin{aligned}
\hat{\varphi}_{i}^{d}= & -\tilde{f}^{x} \chi_{i} \hat{\varphi}_{i}^{x} \\
\hat{\varphi}_{j}^{d}= & -\tilde{f}^{x} \chi_{j} \hat{\varphi}_{j}^{x} \\
\hat{\varphi}_{j}^{x} & =\hat{\varphi}_{i}^{d}-\zeta\left(\hat{w}_{i}-\hat{w}_{j}\right)-(1-\alpha)\left(\hat{t}_{i}-\hat{t}_{j}\right)+\frac{1}{\rho} \hat{\tau}_{i} \\
\hat{\varphi}_{i}^{x}= & \hat{\varphi}_{j}^{d}+\zeta\left(\hat{w}_{i}-\hat{w}_{j}\right)+(1-\alpha)\left(\hat{t}_{i}-\hat{t}_{j}\right)+\frac{1}{\rho} \hat{\tau}_{j} \\
\hat{\varphi}_{i}^{x}= & \hat{\varphi}_{j}^{x}+\frac{1}{k}\left(\hat{w}_{i}-\hat{w}_{j}\right) \\
\hat{P}_{i}= & \tilde{\delta}_{i}\left[\alpha \hat{w}_{i}+(1-\alpha) \hat{t}_{i}+\frac{k-(\sigma-1)}{\sigma-1} \hat{\varphi}_{i}^{d}\right] \\
& +\left(1-\tilde{\delta}_{i}\right)\left[\hat{\tau}_{i}+\alpha \hat{w}_{j}+(1-\alpha) \hat{t}_{j}+\frac{k-(\sigma-1)}{\sigma-1} \hat{\varphi}_{j}^{x}\right] .
\end{aligned}
$$

Reducing this system of equations according to our analysis gives Eqs. (23)-(28) in the main text.

\section{A.3.2 Derivation of the change in the domestic export cutoff, Eq. (30)}

As a first step, in Eqs. (A.17)-(A.19) substitute for the domestic cutoff productivities, $\hat{\varphi}_{i}^{d}$ and $\hat{\varphi}_{j}^{d}$, from Eqs. (A.15) and (A.16). This gives a reduced system of three equations in the four unknowns $\hat{\varphi}_{i}^{x}, \hat{\varphi}_{j}^{x}, \hat{w}_{i}$, and $\hat{w}_{j}$, while the latter two variables are part of each equation as the change in the relative domestic wage rate:

$$
\begin{aligned}
& \hat{\varphi}_{j}^{x}=-\tilde{f}^{x} \chi_{i} \hat{\varphi}_{i}^{x}-\zeta\left(\hat{w}_{i}-\hat{w}_{j}\right)-(1-\alpha)\left(\hat{t}_{i}-\hat{t}_{j}\right)+\frac{1}{\rho} \hat{\tau}_{i} \\
& \hat{\varphi}_{i}^{x}=-\tilde{f}^{x} \chi_{j} \hat{\varphi}_{j}^{x}+\zeta\left(\hat{w}_{i}-\hat{w}_{j}\right)+(1-\alpha)\left(\hat{t}_{i}-\hat{t}_{j}\right)+\frac{1}{\rho} \hat{\tau}_{j} \\
& \hat{\varphi}_{i}^{x}=\hat{\varphi}_{j}^{x}+\frac{1}{k}\left(\hat{w}_{i}-\hat{w}_{j}\right)
\end{aligned}
$$

Make use of Eq. (A.23) to substitute for $\hat{\varphi}_{j}^{x}$ in Eqs. (A.21) and (A.22). This yields

$$
\begin{aligned}
& \left(1+\tilde{f}^{x} \chi_{i}\right) \hat{\varphi}_{i}^{x}=-\left(\zeta-\frac{1}{k}\right)\left(\hat{w}_{i}-\hat{w}_{j}\right)-(1-\alpha)\left(\hat{t}_{i}-\hat{t}_{j}\right)+\frac{1}{\rho} \hat{\tau}_{i} \\
& \left(1+\tilde{f}^{x} \chi_{j}\right) \hat{\varphi}_{i}^{x}=\left(\zeta+\frac{\tilde{f}^{x} \chi_{j}}{k}\right)\left(\hat{w}_{i}-\hat{w}_{j}\right)+(1-\alpha)\left(\hat{t}_{i}-\hat{t}_{j}\right)+\frac{1}{\rho} \hat{\tau}_{j}
\end{aligned}
$$

Jointly, by eliminating the change in relative wage rates, $\hat{w}_{i}-\hat{w}_{j}$, this gives the final equation 
relating a change in the domestic export cutoff to changes in exogenously altered policy changes:

$$
\hat{\varphi}_{i}^{x}=\left[-(1-\alpha) \frac{1+\tilde{f}^{x} \chi_{j}}{k}\left(\hat{t}_{i}-\hat{t}_{j}\right)+\left(\zeta+\frac{\tilde{f}^{x} \chi_{j}}{k}\right) \frac{1}{\rho} \hat{\tau}_{i}+\left(\zeta-\frac{1}{k}\right) \frac{1}{\rho} \hat{\tau}_{j}\right] \mathcal{A}^{-1},
$$

where we define

$$
\begin{aligned}
\mathcal{A} & \equiv\left(1+\tilde{f}^{x} \chi_{j}\right)\left(\zeta-\frac{1}{k}\right)+\left(1+\tilde{f}^{x} \chi_{i}\right)\left(\zeta+\frac{\tilde{f}^{x} \chi_{j}}{k}\right) \\
& =\left[2+\tilde{f}^{x}\left(\chi_{i}+\chi_{j}\right)\right] \zeta-\left[1-\left(\tilde{f}^{x}\right)^{2} \chi_{i} \chi_{j}\right] \frac{1}{k}>0 .
\end{aligned}
$$

From $\zeta>1 / k$ it follows that $\mathcal{A}>0$, which symmetrically depends on the domestic and foreign variables, $\chi_{i}$ and $\chi_{j}$.

The effect of a change in $t_{i}$ on $\varphi_{i}^{x}$ can be expressed as follows

$$
\frac{\hat{\varphi}_{i}^{x}}{\hat{t}_{i}}=-(1-\alpha)\left[(\zeta k-1)+\left(1+\tilde{f}^{x} \chi_{i}\right) \frac{\zeta k+\tilde{f}^{x} \chi_{j}}{1+\tilde{f}^{x} \chi_{j}}\right]^{-1} \in\left(-\frac{\sigma-1}{k} ; 0\right) .
$$

The negative elasticity is strictly smaller than unity (in absolute value). To see this, note that $\zeta k>1$ and, hence, the term in square brackets is strictly larger than one, while $(1-\alpha) \in(0 ; 1)$.

\section{A.3.3 Derivation of aggregate productivity and its change, Eqs. (32) and (33)}

From the definition of average productivity it follows that

$$
\begin{aligned}
\bar{\varphi}_{i} & =\left[\int_{\varphi_{i}^{d}}^{\infty} \varphi^{-1} y_{i}^{d}(\varphi) \frac{g(\varphi)}{1-G\left(\varphi_{i}^{d}\right)} d \varphi+\int_{\varphi_{i}^{x}}^{\infty} \varphi^{-1} y_{i}^{x}(\varphi) \frac{g(\varphi)}{1-G\left(\varphi_{i}^{d}\right)} d \varphi\right]^{-1} \bar{y}_{i} \\
& =\left[\frac{k(\sigma-1)}{k-(\sigma-1)}\left(\frac{w_{i}}{t_{i}}\right)^{1-\alpha} \frac{1}{\beta}\left(\varphi_{i}^{d}\right)^{k}\left(f\left(\varphi_{i}^{d}\right)^{-k}+f^{x}\left(\varphi_{i}^{x}\right)^{-k}\right)\right]^{-1} \bar{y}_{i},
\end{aligned}
$$

where the second equality follows from the specification of the Pareto distribution for productivities and from the two zero cutoff profit conditions for country $i$ as defined as in Eq. (14). Using $\bar{y}_{i} \equiv \bar{y}_{i}^{d}+\chi_{i} \bar{y}_{i}^{x}=k(\sigma-1) /[\beta(k-\sigma)]\left(w_{i} / t_{i}\right)^{1-\alpha}\left(\varphi_{i}^{d}\right)^{k}\left[f\left(\varphi_{i}^{d}\right)^{1-k}+f^{x}\left(\varphi_{i}^{x}\right)^{1-k}\right]$ this reduces to

$$
\bar{\varphi}_{i}=\frac{k-(\sigma-1)}{(k-\sigma)} \frac{f\left(\varphi_{i}^{d}\right)^{1-k}+f^{x}\left(\varphi_{i}^{x}\right)^{1-k}}{f\left(\varphi_{i}^{d}\right)^{-k}+f^{x}\left(\varphi_{i}^{x}\right)^{-k}},
$$

which, rearranged, gives Eq. (32) in the main text.

An alternative expression can be derived by means of Eq. (17) taking into account the relation 
between the two domestic cutoff productivity levels. Accordingly, average productivity follows as

$$
\bar{\varphi}_{i}=\frac{\sigma-1}{(k-\sigma) f^{e}}\left[f\left(\varphi_{i}^{d}\right)^{1-k}+f^{x}\left(\varphi_{i}^{x}\right)^{1-k}\right]
$$

Log-linearising this equation yields

$$
\hat{\bar{\varphi}}_{i}=-(k-1)\left[\psi_{i} \hat{\varphi}_{i}^{d}+\left(1-\psi_{i}\right) \hat{\varphi}_{i}^{x}\right]
$$

where we define $\psi_{i} \equiv 1 /\left(1+\tilde{f}^{x} \chi^{\frac{k-1}{k}}\right)$, which can be shown to be the (initial) share of production for the domestic market in total production; $1-\psi_{i}$ to be the (initial) share of production for the export market. Substituting for $\hat{\varphi}_{i}^{x}$ from Eq. (23) and rearranging terms, we derive the change in aggregate productivity w.r.t. the change in the emissions tax as given as in Eq. (33).

\section{A.3.4 Derivation of the change in the foreign export cutoff, Eq. (34)}

Similar to the derivation of the change in the domestic export cutoff, we start by eliminating the other country's change in its export cutoff in the reduced system of equations. Here substitute for $\hat{\varphi}_{i}^{x}$ in Eqs. (A.21) and (A.22) by means of Eq. (A.23) in order to get:

$$
\begin{aligned}
& \left(1+\tilde{f}^{x} \chi_{i}\right) \hat{\varphi}_{j}^{x}=-\left(\zeta+\frac{\tilde{f}^{x} \chi_{i}}{k}\right)\left(\hat{w}_{i}-\hat{w}_{j}\right)-(1-\alpha)\left(\hat{t}_{i}-\hat{t}_{j}\right)+\frac{1}{\rho} \hat{\tau}_{i} \\
& \left(1+\tilde{f}^{x} \chi_{j}\right) \hat{\varphi}_{j}^{x}=\left(\zeta-\frac{1}{k}\right)\left(\hat{w}_{i}-\hat{w}_{j}\right)+(1-\alpha)\left(\hat{t}_{i}-\hat{t}_{j}\right)+\frac{1}{\rho} \hat{\tau}_{j} .
\end{aligned}
$$

Jointly, by eliminating $\hat{w}_{i}-\hat{w}_{j}$, these two equations can be reduced to

$$
\hat{\varphi}_{j}^{x}=\left[(1-\alpha) \frac{1+\tilde{f}^{x} \chi_{i}}{k}\left(\hat{t}_{i}-\hat{t}_{j}\right)+\left(\zeta-\frac{1}{k}\right) \frac{1}{\rho} \hat{\tau}_{i}+\left(\zeta+\frac{\tilde{f}^{x} \chi_{i}}{k}\right) \frac{1}{\rho} \hat{\tau}_{j}\right] \mathcal{A}^{-1}
$$

Solving for $\hat{\varphi}_{j}^{x} / \hat{t}_{i}$ gives Eq.(34) in the main text.

\section{A.3.5 Derivation of the change in the domestic wage rate, Eq. (36)}

Substituting for $\hat{\varphi}_{i}^{d}$ in Eq. (A.20) from Eq. (A.15) and rearranging gives:

$$
\begin{aligned}
\hat{P}_{i}= & \alpha \hat{w}_{i}+(1-\alpha) \hat{t}_{i}-\tilde{f}^{x} \chi_{i} \frac{k-(\sigma-1)}{\sigma-1} \hat{\varphi}_{i}^{x} \\
& +\left(1-\tilde{\delta}_{i}\right)\left[\hat{\tau}_{i}-\alpha\left(\hat{w}_{i}-\hat{w}_{j}\right)-(1-\alpha)\left(\hat{t}_{i}-\hat{t}_{j}\right)+\frac{k-(\sigma-1)}{\sigma-1}\left(\hat{\varphi}_{j}^{x}+\tilde{f}^{x} \chi_{i} \hat{\varphi}_{i}^{x}\right)\right],
\end{aligned}
$$

where $\tilde{\delta}_{i}$ is defined as in Eq. (29). 
Next, make use of Eq. (A.23) to substitute for $\hat{\varphi}_{j}^{x}$ in Eq. (A.36). Accordingly,

$$
\begin{aligned}
\hat{P}_{i}= & \alpha \hat{w}_{i}+(1-\alpha) \hat{t}_{i}+\frac{k-(\sigma-1)}{\sigma-1}\left[1-\tilde{\delta}_{i}\left(1+\tilde{f}^{x} \chi_{i}\right)\right] \hat{\varphi}_{i}^{x} \\
& +\left(1-\tilde{\delta}_{i}\right)\left[\hat{\tau}_{i}-\left(\zeta-\frac{1}{k}\right)\left(\hat{w}_{i}-\hat{w}_{j}\right)-(1-\alpha)\left(\hat{t}_{i}-\hat{t}_{j}\right)\right],
\end{aligned}
$$

where we make use of the relation $\alpha+[k-(\sigma-1)] /[k(\sigma-1)]=\zeta-1 / k$, which directly follows from the definition of $\zeta$. Next, eliminate $\hat{w}_{i}-\hat{w}_{j}$ by means of Eq. (A.24). This gives:

$$
\hat{P}_{i}=\alpha \hat{w}_{i}+(1-\alpha) \hat{t}_{i}-\frac{\left(1-\tilde{\delta}_{i}\right)}{\sigma-1} \hat{\tau}_{i}+\left[\tilde{f}^{x} \chi_{i}+\frac{k}{\sigma-1}\left(1-\tilde{\delta}_{i}\left(1+\tilde{f}^{x} \chi_{i}\right)\right)\right] \hat{\varphi}_{i}^{x}
$$

Recalling that $\tilde{\delta}_{i}=\left(1+\tau_{i} \tilde{f}^{x} \chi_{i}\right)^{-1}$ from Eq. (29) we can rewrite Eq. (A.38) as:

$$
\hat{P}_{i}=\alpha \hat{w}_{i}+(1-\alpha) \hat{t}_{i}-\frac{\tau_{i} \tilde{f}^{x} \chi_{i}}{1+\tau_{i} \tilde{f}^{x} \chi_{i}}(\sigma-1)^{-1} \hat{\tau}_{i}+\left[\tilde{f}^{x} \chi_{i}+\frac{k}{\sigma-1}\left\{1-\frac{1+\tilde{f}^{x} \chi_{i}}{1+\tau_{i} \tilde{f}^{x} \chi_{i}}\right\}\right] \hat{\varphi}_{i}^{x}
$$

Finally, setting $\hat{P}_{i}=0$ (by choice of the numéraire) and $\hat{\tau}_{i}=0$ (by choice of the analysis), we get

$$
\frac{\hat{w}_{i}}{\hat{t}_{i}}=-\frac{1-\alpha}{\alpha}-\frac{1}{\alpha}\left[\tilde{f}^{x} \chi_{i}+\frac{k}{\sigma-1}\left\{1-\frac{1+\tilde{f}^{x} \chi_{i}}{1+\tau_{i} \tilde{f}^{x} \chi_{i}}\right\}\right] \frac{\hat{\varphi}_{i}^{x}}{\hat{t}_{i}}
$$

The sign of the overall effect is ex ante ambiguous as it consists of two opposing effects. On the one hand, there is a negative direct effect of the change in $t_{i}$ (via the price index). This effect is the same as in the closed economy. On the other hand, there is an additional, indirect effect through reallocation represented by the change in the export cutoff. This second effect is larger than zero. This follows as $\hat{\varphi}_{i}^{x} / \hat{t}_{i}<0$, while the term in square brackets is positive. To see this, note that the term in curly brackets is $\in[0 ; 1)$, while it becomes zero in the absence of an initial (domestic) import tariff, i.e. if $\tau_{i}=1$. We can rewrite Eq. (A.40) using Eq. (30) to substitute for $\hat{\varphi}_{i}^{x} / \hat{t}_{i}$ and get Eq. (36) in the main text

In order to proof the negative sign of the effect, rewrite Eq. (36) to get:

$$
\frac{\hat{w}_{i}}{\hat{t}_{i}}=-\frac{1-\alpha}{\alpha \mathcal{A} k}\left(\mathcal{A} k-\left(1+\tilde{f}^{x} \chi_{j}\right)\left[\tilde{f}^{x} \chi_{i}+\frac{k}{\sigma-1}\left\{1-\frac{1+\tilde{f}^{x} \chi_{i}}{1+\tau_{i} \tilde{f}^{x} \chi_{i}}\right\}\right]\right) .
$$

Since $(1-\alpha) / \alpha$ and $\mathcal{A} k$ are both positive, it is sufficient to determine the sign of the term in parentheses to learn about the sign of the entire effect. Using the definition of $\mathcal{A}$ and noting 
that $\zeta=\alpha+1 /(\sigma-1)$, it is straightforward to rewrite the term in parentheses as

$$
\mathcal{C}_{i} \equiv\left(1+\tilde{f}^{x} \chi_{i}\right)(\zeta k-1)+\left(1+\tilde{f}^{x} \chi_{j}\right)\left(\alpha k+\frac{k}{\sigma-1} \frac{1+\tilde{f}^{x} \chi_{i}}{1+\tau_{i} \tilde{f}^{x} \chi_{i}}\right) \in(0 ; \mathcal{A} k)
$$

which is strictly positive since all terms in parentheses are greater than zero as $\zeta k>1$. Moreover, note that this positive term is necessarily smaller than $\mathcal{A} k$. Hence, dividing it by $\mathcal{A} k$ gives a term $\in(0 ; 1)$ as proposed in the main text.

\section{A.3.6 Derivation of the change in the foreign wage rate}

In order to derive the change in the foreign wage rate, make use of Eqs. (A.21)-(A.23) and eliminate the export cutoff productivity levels of both countries to get an expression for the change in the relative wage rate, $\hat{w}_{j}-\hat{w}_{i}$. Accordingly,

$$
\begin{aligned}
\hat{w}_{j}-\hat{w}_{i}= & {\left[(1-\alpha)\left[2+\tilde{f}^{x}\left(\chi_{i}+\chi_{j}\right)\right]\left(\hat{t}_{i}-\hat{t}_{j}\right)-\left(1+\tilde{f}^{x} \chi_{j}\right) \frac{1}{\rho} \hat{\tau}_{i}\right.} \\
& \left.+\left(1+\tilde{f}^{x} \chi_{i}\right) \frac{1}{\rho} \hat{\tau}_{j}\right] \mathcal{A}^{-1}
\end{aligned}
$$

Setting $\hat{t}_{j}=\hat{\tau}_{i}=\hat{\tau}_{j}=0$ by choice of our analysis and rearranging gives Eq. (38) in the main text. The positive sign directly follows from the definition of $\mathcal{A}>0$.

By means of Eq. (36) for $\hat{w}_{i} / \hat{t}_{i}$, we can derive the elasticity of the foreign wage rate w.r.t. the domestic emissions tax as

$$
\frac{\hat{w}_{j}}{\hat{t}_{i}}=-\frac{1-\alpha}{\alpha \mathcal{A} k}\left(\mathcal{C}_{i}-\left[2+\tilde{f}^{x}\left(\chi_{i}+\chi_{j}\right)\right] \alpha k\right) .
$$

Since both $(1-\alpha) / \alpha$ and $\mathcal{A} k$ are positive, it is sufficient to determine the sign of the term in parentheses to learn about the sign of the entire effect. Using the definition of $\mathcal{C}_{i}$ from Eq. (A.42) and and noting that $\zeta k=\alpha k+k /(\sigma-1)$, we can show that the term in parentheses is equal to

$$
\left(1+\tilde{f}^{x} \chi_{i}\right)\left(\frac{k}{\sigma-1}-1\right)+\left(1+\tilde{f}^{x} \chi_{j}\right) \frac{k}{\sigma-1}\left(\frac{1+\tilde{f}^{x} \chi_{i}}{1+\tau_{i} \tilde{f}^{x} \chi_{i}}\right) \in\left(0 ; \mathcal{C}_{i}\right),
$$

which is strictly positive, since all terms are greater than zero as $k>\sigma-1$, and strictly smaller than $\mathcal{C}_{i}$. 


\section{References}

Aichele, R. And G. Felbermayr (2015): "Kyoto and Carbon Leakage: An Empirical Analysis of the Carbon Content of Bilateral Trade," Review of Economics and Statistics, 97, 104-115.

Ambec, S., M. A. Cohen, S. Elgie, and P. Lanoie (2013): "The Porter Hypothesis at 20: Can Environmental Regulation Enhance Innovation and Competitiveness?" Review of Environmental Economics and Policy, 7, 2-22.

Andersen, D. C. (2016): "Credit Constraints, Technology Upgrading, and the Environment," Journal of the Association of Environmental and Resource Economists, 3, 283-319.

(2018): "Accounting for Loss of Variety and Factor Reallocations in the Welfare Cost of Regulations," Journal of Environmental Economics and Management, 88, 69-94.

Anouliès, L. (2017): "Heterogeneous Firms and the Environment: A Cap-and-Trade Program," Journal of Environmental Economics and Management, 84, 84-101.

Antweiler, W., B. R. Copeland, and M. S. Taylor (2001): "Is Free Trade Good for the Environment?" American Economic Review, 91, 877-908.

Barrows, G. And H. Ollivier (2018): "Cleaner Firms or Cleaner Products? How Product Mix Shapes Emission Intensity from Manufacturing," Journal of Environmental Economics and Management, 88, 134-158.

Baylis, K., D. Fullerton, And D. H. Karney (2014): "Negative Leakage," Journal of the Association of Environmental and Resource Economists, 1, 51-73.

Bernard, A. B., S. J. Redding, and P. K. Schott (2007): "Comparative Advantage and Heterogeneous Firms," Review of Economic Studies, 74, 31-66.

CAO, J., L. D. QIU, AND M. Zhou (2016): "Who Invests More in Advanced Abatement Technology? Theory and Evidence," Canadian Journal of Economics/Revue canadienne d'économique, 49, 637-662.

Cherniwchan, J. (2017): "Trade Liberalization and the Environment: Evidence from NAFTA and U.S. Manufacturing," Journal of International Economics, 105, 130-149.

Cherniwchan, J., B. R. Copeland, and M. S. Taylor (2017): "Trade and the Environment: New Methods, Measurements, and Results," Annual Review of Economics, 9, 59-85.

Copeland, B. R. and M. S. Taylor (1994): "North-South Trade and the Environment," Quarterly Journal of Economics, 109, 755-787. $7-71$.

(2004): "Trade, Growth, and the Environment," Journal of Economic Literature, 42,

(2005): "Free Trade and Global Warming: A Trade Theory View of the Kyoto Protocol," Journal of Environmental Economics and Management, 49, 205-234.

Demidova, S. and A. Rodríguez-Clare (2009): "Trade Policy under Firm-Level Heterogeneity in a Small Economy," Journal of International Economics, 78, 100-112.

Di Maria, C. And E. V. D. Werf (2008): "Carbon Leakage Revisited: Unilateral Climate Policy with Directed Technical Change," Environmental \& Resource Economics, 39, 55-74. 
EgGer, H. And U. Kreickemeier (2009): "Firm Heterogeneity and the Labor Market Effects of Trade Liberalization," International Economic Review, 50, 187-216.

EthieR, W. J. (1982): "National and International Returns to Scale in the Modern Theory of International Trade," American Economic Review, 72, 389.

Felbermayr, G., B. Jung, and M. Larch (2013): "Optimal Tariffs, Retaliation, and the Welfare Loss from Tariff Wars in the Melitz Model," Journal of International Economics, 89, $13-25$.

Forslid, R., T. Okubo, and M. Sanctuary (2017): "Trade Liberalization, Transboundary Pollution, and Market Size," Journal of the Association of Environmental and Resource Economists, 4, 927-957.

Forslid, R., T. Okubo, And K. H. Ulltveit-Moe (2018): "Why Are Firms that Export Cleaner? International Trade, Abatement and Environmental Emissions," Journal of Environmental Economics and Management, 91, 166-183.

Grossman, G. M. and A. B. Krueger (1993): "Environmental Impacts of a North American Free Trade Agreement," in The Mexico-U.S. Free Trade Agreement, ed. by P. M. Garber, Cambride, MA: The MIT Press, 13-56.

Gürtzgen, N. And M. Rauscher (2000): "Environmental Policy, Intra-Industry Trade and Transfrontier Pollution," Environmental \& Resource Economics, 17, 59-71.

Holladay, J. S. (2016): "Exporters and the Environment," Canadian Journal of Economics/Revue canadienne d'économique, 49, 147-172.

Holladay, J. S., M. Mohsin, and S. Pradhan (2018): "Emissions Leakage, Environmental Policy and Trade Frictions," Journal of Environmental Economics and Management, 88, 95113.

Konishi, Y. And N. TARui (2015): "Emissions Trading, Firm Heterogeneity, and Intra-industry Reallocations in the Long Run," Journal of the Association of Environmental and Resource Economists, 2, 1-42.

Kreickemeier, U. And P. M. Richter (2014): "Trade and the Environment: The Role of Firm Heterogeneity," Review of International Economics, 22, 209-225.

LaPlue, L. D. (2019): "The Environmental Effects of Trade Within and Across Sectors," Journal of Environmental Economics and Management, 94, 118-139.

Larch, M. And J. Wanner (2017): "Carbon Tariffs: An Analysis of the Trade, Welfare, and Emission Effects," Journal of International Economics, 109, 195-213.

Levinson, A. (2009): "Technology, International Trade, and Pollution from US Manufacturing," American Economic Review, 99, 2177-2192.

LI, Z. AND J. Sun (2015): "Emission Taxes and Standards in a General Equilibrium with Entry and Exit," Journal of Economic Dynamics and Control, 61, 34-60.

Melitz, M. J. (2003): "The Impact of Trade on Intra-Industry Reallocations and Aggregate Industry Productivity," Econometrica, 71, 1695-1725.

NAJjar, N. AND J. Cherniwchan (2018): "Environmental Regulations and the Clean-Up of Manufacturing: Plant-Level Evidence From Canada," University of Alberta School of Business Research Paper No. 2018-701. 
Pflüger, M. (2001): "Ecological Dumping under Monopolistic Competition," Scandinavian Journal of Economics, 103, 689-706.

Porter, M. E. AND C. VAn Der Linde (1995): "Toward a New Conception of the Environment-Competitiveness Relationship," Journal of Economic Perspectives, 9, 97-118.

Qiu, L. D., M. Zhou, And X. Wei (2018): "Regulation, Innovation, and Firm Selection: The Porter Hypothesis under Monopolistic Competition," Journal of Environmental Economics and Management.

Richter, P. M. And A. Schiersch (2017): " $\mathrm{CO}_{2}$ Emission Intensity and Exporting: Evidence from Firm-level Data," European Economic Review, 98, 373-391.

Shapiro, J. S. And R. Walker (2018): "Why Is Pollution from US Manufacturing Declining? The Roles of Environmental Regulation, Productivity, and Trade," American Economic Review, 108, 3814-54.

Tombe, T. And J. Winter (2015): "Environmental Policy and Misallocation: The Productivity Effect of Intensity Standards," Journal of Environmental Economics and Management, $72,137-163$.

UNFCCC (2015): "Paris Agreement," https://unfccc.int/files/meetings/paris_nov_ 2015/application/pdf/paris_agreement_english_.pdf. 